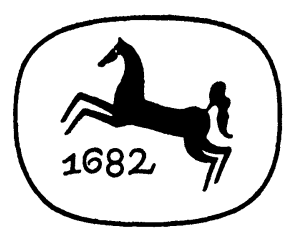

Dramenform UND KLASSENSTRUKTUR 
Hannelore Schlaffer

\title{
Dramenform und Klassenstruktur
}

Eine Analyse der dramatis persona

»Volk «

\author{
J. B. Metzlersche \\ Verlagsbuchhandlung \\ Stuttgart
}


Die vorliegende Arbeit wurde 1971 von der Philosophischen Fakultät der Universität Erlangen-Nürnberg als Dissertation angenommen.

D 29

ISBN 978-3-476-00246-4

ISBN 978-3-476-03003-0 (eBook)

DOI 10.1007/978-3-476-03003-0

( ) Springer-Verlag GmbH Deutschland 1972

Ursprünglich erschienen bei J. B. Metzlersche Verlagsbuchhandlung und Carl Ernst Poeschel Verlag GmbH in Stuttgart 1972. 


\section{INHALT}

Einleitung

1. Beschreibung der Figur 9

1. Abgrenzungen 9

2. Konstante Eigenschaften 18

$\begin{array}{ll}\text { 3. Schauplätze } & 27\end{array}$

II. Figur und Form 32

1. Die komische Tradition der Figur Volk in der Tragödie 32

2. Volk und Held 43

3. Die Veränderung der Form

4. Geschichte als Interpretationshorizont des Dramas 62

III. Geschichte der Figur

Historische Analysen der dramatis persona Volk in Dramen von Goethe bis Brecht

$\begin{array}{lr}\text { Schluß } & 107\end{array}$

$\begin{array}{ll}\text { Anmerkungen } & 110\end{array}$

Literaturverzeichnis $\quad 126$

$\begin{array}{ll}\text { 1. Quellen } & 126\end{array}$

2. Bibliographie zur Soziologie des Dramas 127 